\title{
ФИЛОСОФИЯ
}

DOI: 10.17805/ggz.2019.1.6

\section{Проблема социально-всеобщего в контексте конкретно-всеобщей теории развития}

\author{
В. В. Коромыслов
}

Пермский государственный аграрно-технологический университет имени Д. Н. Прянишникова

В статье рассматривается проблема объективно-всеобщих основ социиального бытия. Опираясь на конкретно-всеобщую теорию развития $и$ концуепциию конкретно-всеобщего, автор выводит основные черты соичиально-всеобщего и проводит анализ его роли в конструировании социальной реальности. Помимо этого исследуется структура социально-всеобщего и механизмы его развития. Исследование в данном направлении позволяет найти ключ к решению многих актуальных проблем современности.

Проводится краткий обзор достижений по данной проблематике. Показывается, что наибольших успехов в этой области достигли Ш. В. Мисабишвили, В.В. Орлов и другие представители конкретно-всеобщей теории развития. В рамках конкретно-всеобщей теории развития дается принциииальное решение проблемы сочиильно-всеобщего, выявляются его основные характеристики. Социально-всеобщее - это, с одной сторонь, единство абстрактно-всеобщих моментов в их конкретной взаимосвязи, а с другой оно есть закон или принциип организации и развития общества. Социиальновсеобщее организуется в виде сущзностных сил человека. Оно обладает способностью развития путем углубления в себя, в человеческую сущьность.

Показано, что сочиально-всеобщее является продолжением единого закономерного мирового процесса развития материи в изелом. Обосновывается мысль о том, что сочиально-всеобщее имеет различные уровни, отличающиеся по характеру предопределения течения событий. Наиболее глубинные пласты сочиально-всеобщего связываются с глобальными тенденциями, закономерностями и законами развития общества, а поверхностные пласты - с взаимосвязями, конструирующими уникальные жсизненные ситуации. Отмечается, что для прогрессивного развития общества более важно познание наиболее глубинных пластов социально-всеобщего, сведения о которых должны накапливаться и сохраняться в культуре общества и механизмах его функционирования.

Ключевые слова: сочиально-всеобщее; конкретно-всеобщуее; взаимосвязи в обществе; законы развития общества; сущуность человека; человек 


\title{
The Problem of the Socio-Universal in the Context of the Concrete Universal Theory of Development
}

\author{
V. V. Koromyslov \\ D. N. Pryanishnikov Perm State Agricultural Academy
}

The article considers the problem of the objectively universal foundations of social life. Relying on the concrete universal theory of development and the conception of the concrete and universal, the author presents the basic features of the socio-universal and analyzes its role in the construction of social reality. In addition, we study the structure of the socio-universal and the mechanisms of its development. The research in this field allows us to find the key to solving many of the pressing problems of our time.

We make a brief overview of the achievements in this field of research. It is shown that Sh. V. Misabishvili, V. V. Orlov and other followers of the concrete universal theory of development have attained their greatest success in this area. Within the framework of the concrete universal theory of development, a fundamental solution to the problem of the socio-universal is given. The researchers have revealed its essential characteristics. The socio-universal is, on the one hand, the unity of abstract and universal moments in their particular interrelations, and, on the other hand, it is a law or principle of the organization and development of the society. The socio-universal is organized in the form of human essential forces. It is capable to develop itself in a way of deepening in the human essence.

It is shown that the socio-universal is a continuation of a single world process of the development of the matter that conforms to the laws of nature in general. We argue for the idea that the socio-universal has different levels that differ in the nature of predetermination of the current events. The deepest layers of the socio-universal are related to global trends and the laws of social development. The surface layers of the socio-universal are related to interrelations that construct unique life situations. It is noted that for the progressive development of society it is more important to perceive the deepest layers of the socio-universal. Data on these layers must be accumulated and stored in the culture of the society and the mechanisms of its functioning.

Keywords: the socio-universal; the concrete universal; interrelations in society; laws of social development; human essence; the human

\section{ВВЕДЕНИЕ}

В силу таких тенденций современной молодежной культуры как рост пренебрежительного отношения к истинности, объективности, различным нормам и правилам, размывание сложившихся смысловых значений, перевертывание ценностных ориентиров и т. д. в современной культуре расшатывается тот ее стержень, фундамент, в котором аккумулировались наиболее ценные пласты многовекового опыта и знаний человечества. В результате происходит отрыв личности от понимания действительности, существующих в ней взаимосвязей, что в конечном счете приводит к забвению гуманистиче- 
ских идеалов. Многие негативные, кризисные проявления в современном обществе являются прямым следствием этих тенденций в мировой культуре. Отсюда важной задачей представляется беспристрастное исследование всеобщих основ человеческого бытия и объективных механизмов, конструирующих смыслы социального. Такое исследование должно способствовать более глубокому пониманию объективных основ нравственности и их роли в формировании системы ценностей общества на том или ином этапе его развития. Ключом к решению этой проблемы, на наш взгляд, является концепция социально-всеобщего в рамках конкретно-всеобщей теории развития.

\section{КОНЦЕПЦИЯ СОЦИАЛЬНО-ВСЕОБЩЕГО}

На наш взгляд, научное понимание проблемы социально-всеобщего складывается в марксисткой философии. В марксизме весь мир понимается как единое бесконечное материальное целое, находящееся в процессе непрерывного развития, перехода от низших ступеней к высшим. Человек является закономерным результатом мирового процесса развития материи, высшей ее формой. Таким образом, человек и всеобщее содержание мира оказываются субстанциально единь, обладают генетическим родством. Сущность человека понимается в тесной связи с природой объективно всеобщего и всеобщими закономерностями развития (Философия пограничных проблем науки, 1967-1975; Концепция единого закономерного мирового процесса и современность, 1987; Новые идеи в философии, 1992-2015).

Всеобщее содержание человека в марксистской философии понимается в его тесной связи с особеннылм, многообразием хитросплетений его индивидуальных проявлений и практических результатов деятельности. Так, это всеобщее принципиально невозможно выявить путем формальной абстракции из совокупности всех отдельных индивидов. Это было показано К. Марксом на примере тех трудностей, которые возникают с понятием «человек», с определением его сущности. Простое обобщение общих черт, свойств в индивидах еще не дает полного представления о сущности человека. Человек не может быть понят вне его истории, вне социального поля, в котором он существует, себя осуществляет, и которым был в известном смысле порожден и постоянно его сам порождает, преобразует. И в этом смысле становится понятным замечание К. Маркса в отношении понимания человека Л. А. Фейербахом: «...сущность человека не есть абстракт, присущий отдельному индивиду. В своей действительности она есть совокупность всех общественных отношений» (Маркс, 1955: 3).

Так, сущность человеческого рода может быть понята лишь в контексте исторически меняющихся отношений между людьми, на основе анализа тех закономерностей, которые образуются в практических результатах этих отношений. Э. В. Ильенков пишет: «Сущность человеческой природы вообще можно выявить только через научно-критический анализ “всей совокупности”, “всего ансамбля” социально-исторических отношений человека к человеку, через конкретное исследование закономерностей, в русле которых в 
действительности протекал и протекает процесс рождения эволюции как человеческого общества в целом, так и индивида» (Ильенков, 1984: 279).

Отдельный индивид лишь постольку является человеком, поскольку он реализует через свою индивидуальность родовое, всеобщее в человеке, усвоенный им фрагмент культуры (там же). А потому всеобщее в человеке неправомерно рассматривать отдельно, оторвано от своего выражения в индивидуальных проявлениях. Родовое, всеобщее в человеке существует через индивидуальное, при тесном единстве с ним, а индивидуальное потенциально заложено во всеобщем в свернутом виде, в виде зачатка, зародыша, который развертывает свое содержание по мере действия механизма конкретновсеобщего, его обуславливающего. Именно поэтому сущность человека рассматривается К. Марксом как единство родовой и индивидуальной сущности. Он пишет: «Индивидуальная и родовая жизнь человека не являются чем-то различнылм, хотя... способ существования индивидуальной жизни бывает либо более особенным, либо более всеобщим проявлением родовой жизни, а родовая жизнь бывает либо более особенной, либо всеобщей индивидуальной жизнью» (Маркс, 1974: 119; курсив источника. - В. К.).

В прошлых наших исследованиях мы показали недостатки концепции понимания всеобщего как «общего-сходного» и обосновали целесообразность понимания всеобщего как «конкретно-всеобщего» (Коромыслов, 2008). Точно также всеобщее в человеке представляет собой не сплошную слитность родовой одинаковости индивидов, а конкретную «реальность, внутри себя многократно и многообразно расчлененную на особенные (отдельные) сферы, взаимно друг друга дополняющие, друг от друга, по существу, зависящие и потому сцепленные воедино узами общности происхождения...» (Ильенков, 1984: 280).

Специальный анализ всеобщего содержания в человеке проводился Ш. В. Мисабишвили (Мисабишвили, 1971). Однако в его понимании всеобщего нет четкого разделения понятий общего-сходного и конкретновсеобщего. Он употребляет этот термин то в первом, то во втором его значении. Так, он пишет: «Всеобщее - это категория, отражающая в себе существенные признаки, присущие всем единичным предметам и явлениям. Всеобщее это то, что лежит в основе многообразия мира и раскрывает закономерный характер движения материи. <..> Социальное всеобщее - наиболее существенный признак (закон), действующий во всех явлениях и предметах данного класса» (Мисабишвили, 1971: 47, 86; курсив источника. - B. К.).

В конечном счете его понимание всеобщего напрямую связывается с повторяемостью, с обобщением наиболее общих действий и проявлений (там же: 87, 105), поэтому его исследование проблемы всеобщего в человеке носит ограниченный характер. Тем не менее, он выходит за пределы исследования общего-сходного в человеке и отмечает некоторые особенности подлинно-всеобщего в нем.

Так, он связывает всеобщее в человеке с существующими в обществе взаимосвязями (там же: 106), отмечает, что действительные законы исторического развития, в качестве всеобщего, «завуалированы, скрыты от непо- 
средственного наблюдения и изучения», существуют в не наглядной форме (там же: 67). Такое всеобщее выражает сам способ взаимодействия общего, особенного и единичного (там же: 84).

Ш. В. Мисабишвили также отмечает, что всеобщее в человеке связано со способом производства своего бытия (там же: 88, 91). Однако всеобщее в человеке им понимается в отрыве от всеобщего природного мира. Им исследуется всеобщее, прежде всего, не в качестве глубинных законов и закономерностей развития общества, являющихся продолжением и своеобразным проявлением наиболее глубинных законов и закономерностей природного мира, а в качестве всеобщих и общих проявлений человеческой жизнедеятельности, всеобщих черт и признаков (там же: 86-92). Так, Мисабишвили рассматривает всеобщее содержание в отношении человека, а не мира в целом, т. е. понятое как человечество, определенное общество, конкретная общественно-экономическая формация, страна и т. д., не затрагивая проблему выражения в человеке объективно всеобщих моментов и законов природного мира, которые и лежат в основе, конструируют указанные формы всеобщности в качестве собственных проявлений, особенного всеобщего.

Сходные представления о всеобщем в человеке развиваются К. Н. Любутиным и П. Н. Кондрашевым (Любутин, Кондрашев, 2007), которые раскрывают всеобщее содержание в повседневном человеческом бытии.

Общий подход к проблеме всеобщего в человеке был сформулирован также в работе А. Н. Шиминой (Шимина, 1982). Однако в ее понимании всеобщее также четко не различается от общего-сходного, что обедняет теоретическую ценность ее исследования в отношении решения данной проблемы.

Новый импульс решение проблемы всеобщего в человеке получило в свете предложенной В. В. Орловым концепции, согласно которой моменты объективного всеобщего природного мира образуют каркас сущности человека со всем ее богатством социально-всеобщего содержания (Орлов, 1999: 96-105, 2000).

Обобщив достижения исследований в рамках концепции конкретновсеобщего, представления о всеобщем в человеке Ш. В. Мисабишвили и концепцию человека в связи со всеобщим В. В. Орлова, мы можем выделить наиболее принципиальные черты выражения подлинно-всеобщего в человеке. Во-первых, всеобщее в человеке связано с субстанцииальностью, конкретной формой взаимодействия всего особенного и единичного в человеке. Во-вторых, оно составляет универсальную, потенциально бесконечную человеческую сущуность. В-третьих, существуя в качестве всеобщих сторон и взаимосвязей социальной действительности, оно составляет закон или принцุип организацуии и развития общества. В-четвертых, оно является единством абстрактно-всеобщих моментов в их конкретной взаимосвязи. В-пятых, уникальный синтез абстрактно-всеобщих моментов в человеческом бытии образует некие цельные моменты - сущностные силы человека. В-шестых, подлинно всеобщее в человеке особым образом содержит в себе все многообразие особенного и единичного, индивидуального социальной реальности. В-седьмых, оно обладает способностью развития путем углубления в себя, в 
человеческую сущность, что выражается в усложнении, обогащцении, уплотнении социильной действительности, все более тесном переплетении ее абстрактно-всеобщих сторон и связей. Другими словами, развитие социальновсеобщего заключается в раскрытии заложенного в нем потенциала, развертылании богатства его содержания относительно его наиболее общей сути, наиболее общзего принципа, закона.

Итак, конкретно-всеобщее в человеке в своей целостности представляет собой закон организации и развития общества. По-видимому, этот закон не должен рассматриваться в отрыве от закона развития мира в целом, а является своеобразным его выражением и продолжением, поскольку развитие высшей формы материи в едином закономерном историческом процессе является своеобразным выражением и продолжением единого закономерного мирового процесса развития материи в целом (ЕЗМП).

Согласно конкретно-всеобщей теории развития ЕЗМП характеризуется закономерностью конвергенции, заключающейся в неуклонном закономерном сокращении распространенности или объема форм материи при переходе от низших ступеней к высшим, и закономерностью аккумуляции, включения основного содержания низших форм материи в высшие (Философия пограничных проблем науки, 1967-1975; Концепция единого закономерного мирового процесса и современность, 1987; Орлов, 1999: 90-92). В результате по мере развития в каждой последующей форме материи материальная субстанция мира выражается во все более миниатюрных, но при этом все более полно выражающими ее целое и свойственную ей тенденцию, частях. Отдельные объекты физической, химической, биологической форм материи различаются степенью их «субстанциальности», способностью определять себя изнутри, т. е. становятся в этом отношении все более подобными миру как целому. В человеке такое свойство выражается в своей наиболее развитой форме. Человек - единственное в мире существо, способное производить себя, собственное бытие и сущность. А поскольку появление такой особенности человеческого существа продиктовано той необходимостью, которая проходит через весь процесс развития материи (а значит и подготовлено всем этим процессом), то, по-видимому, через это свойство человека выражается всеобщий закон развития реальности как целого, т. е. через человека, через его способность к самоопределению, универсальной деятельности, материя обретает наиболее эффективное средство реализации заложенной в ней необходимости (к развитию) (Козин, 1994; Барг, 1997). Чем более свободно и разносторонне человек осуществляет свою деятельность, чем более раскрывает потенциальное богатство своей природы, собственных сущностных сил, тем в большей мере он реализует необходимость, заложенную в материи, ибо его свобода в конечном счете связана с познанием и реализацией этой необходимости. Человек, осуществляя собственную необходимость, осуществляет вместе с тем и необходимость материи.

Таким образом, разумно будет предположить, что человеческая деятельность по построению своего бытия и ее тенденция к росту сознательности этого процесса, все более глубокому познанию законов природы и обще- 
ства и их воплощению в человеческой практике, является в каком-то смысле выражением всеобщего закона развития объективной реальности как целого. Тогда выявленный в рамках марксистской философии всеобщий закон исторического развития, связанный поступательным движением к созданию условий для наиболее полной и всесторонней реализации универсальной человеческой сущности, развития всех творческих возможностей индивида (Васильева, 1999; Мусаелян, 2006), действительно можно считать своеобразным продолжением и дополнением закона развития объективной реальности как целого.

Такой закон, очевидно, лежит в основе конкретно-всеобщего содержания человеческого бытия, составляет наиболее глубинные, фундаментальные его пласты, определяя магистральное направление развития общества. Поэтому данное направление, по-видимому, связано со все более глубоким пониманием взаимосвязей и закономерностей человеческой действительности и реализацией этих знаний в практической деятельности человека, в совершенствовании условий жизни, культуре общества и его языке. И в этом смысле общественный прогресс связан с аккумуляцией в культуре, языке (особенно научном), в практических результатах знаний о наиболее глубинных пластах подлинно-всеобщего. В этом контексте подлинно-всеобщее в обществе связано с истиной, объективностью, общечеловеческими нормами, ценностями, идеалами, общественными порядками и механизмами, со всем необходимым в отношении человеческой сущзности содержанием. Тогда произвольность, стихийность исторического процесса, сопровождающаяся ошибками, заблуждениями, стереотипами, ложными ориентирами, а значит и кризисами, глобальными проблемами общества, - связаны с пренебрежением, упрощенным пониманием и утратой глубинного пласта подлинно всеобщего содержания.

В то же время такое случайное в отношении человеческой сущности содержание также является своеобразным выражением подлинно всеобщего, которое, однако, не отражает сущности его наиболее общего закона, принципа развития. Дело в том, что подлинно всеобщее, обладая способностью к изменению, развитию, тем не менее, содержит в себе некий неизменнылй фундамент, выражающий его сущуность, принщии развертывания (Орлов, 1999: 133-135).

Именно этот глубинный его пласт и аккумулируется в человеческой культуре по мере познания действительности. Тогда как подвижное содержание конкретно-всеобщего, являясь, с одной стороны, выражением этого наиболее глубинного пласта, с другой, - существует через особенное и единичное, через свойственные им различия и противоречия, и поэтому в своей полноте совпадает с социальной реальностью в целом. Любая конкретноисторическая ситуация и жизненная ситуация индивида представляют собой конкретное выражение всеобщих взаимосвязей бытия, однако ключевую роль в них играют наиболее глубинные пласты этого всеобщего, выражающие его наиболее общую суть, ибо они определяют наиболее общие тенденции, закономерности и законы развития. В то же время в индивидуальном 
человеческом бытии они не имеют силы жесткого предопределения, их действие проявляется как тенденция развития ситуации, более явно и точно обнаруживающая себя в отдаленной перспективе и среди больших масс людей. Развитие ситуации определяется не только тем, в какое отношение индивид, общество встают к наиболее глубинным взаимосвязям, но и тем, какое отношение у них возникает к реализующимся на данный момент взаимосвязям. Если последнее определяет ближайшую, то первое, как уже говорилось, отдаленную перспективу.

\section{ЗАКЛЮЧЕНИЕ}

Как мы ранее выяснили, конкретно-всеобщее образует в социальной действительности некие свои цельные узловые моменты, которые мы называем сущностными силами человека. Тогда глубинный пласт подлинно всеобщего, по-видимому, будет составлять их внутренние механизмы, которые делают, например, труд - трудом, свободу - свободой, а справедливость справедливостью. В то время как подвижное содержание подлинно всеобщего, по-видимому, связано с конкретной формой их существования в действительности. В этом свете развитие общества связано со все более глубоким пониманием этих механизмов и построением общества на основе этих знаний. Чему будет соответствовать процесс углубления в каждую из этих сущностных сил, развертывание богатства содержания составляющих их механизмов. Что подобно развитию сущности человека в целом сопровождается усложнением, более тесным переплетением, конструирующих эти сущностные силы, всеобщих сторон и связей (усложнение форм свободы, труда, справедливости и т. д.). А поскольку в этих механизмах сущностных сил, составляющих их конструкциях из всеобщих моментов, содержится алгоритм: «если - то» (задающий тот или иной результат, при тех или иных условиях), то поэтому их исследование будет являться значительным шагом вперед в сторону конкретно-всеобщего подхода, дающего возможность изучения уникального измерения социальной действительности (Коромыслов, 2004, 2006, 2008).

Таким образом, выявление структуры и механизмов функционирования наиболее глубинных пластов всеобщего, наиболее существенных для общества и личности взаимосвязей и закономерностей, с тем чтобы в дальнейшем через систему образования, через культуру привить эти знания индивидам это есть путь к созданию духовно совершенного и процветающего общества.

\section{СПИСОК ЛИТЕРАТУРЫ}

Барг, О. А. (1997) Человек и мир: как материя заставляет человека ее усложнять // Новые идеи в философии : межвуз. сб. науч. трудов по мат. Общероссийской науч. конф., проходившей в Перми 13-15 апреля 1997 г. / гл. ред. В. В. Орлов. Пермь : Изд-во Перм. ун-та. Вып. 6. 164 с. С. 55-59.

Васильева, Т. С. (1999) Всеобщий исторический закон // Новые идеи в философии : межвуз. сб. науч. трудов по мат. Общероссийской науч. конф., 
проходившей в Перми 12-14 апреля 1999 г. / гл. ред. В. В. Орлов. Пермь : Изд-во Перм. ун-та. Вып. 8. 316 с. С. 23-27.

Ильенков, Э. В. (1984) Диалектическая логика: очерки истории и теории. 2-е изд. М. : Политиздат. 320 с.

Козин, Н. Г. (1994) Необходимость человека // Новые идеи в философии : межвуз. сб. науч. трудов по мат. Общероссийской науч. конф., проходившей в Перми 10-12 апреля 1994 г. / гл. ред. В. В. Орлов. Пермь : Изд-во Перм. ун-та. Вып. 2. 227 с. С. 100-109.

Концепция единого, закономерного мирового процесса и современность (1987) : мат. Всесоюзной конф., проходившей 24-28 марта 1987 г. / гл. ред. В. В. Орлов. Пермь : Изд-во Пермского ун-та. 327 с.

Коромыслов, В. В. (2004) Сущность человека и проблема всеобщего // Новые идеи в философии: философия в современной России : межвуз. сб. науч. трудов (по мат. Общероссийской науч. конф., Пермь. 14-16 апреля 2004 г.) : в 2 т. / гл. ред. В. В. Орлов. Пермь : Изд-во Пермского ун-та. Вып. 13. T. 1.292 c. C. $214-218$.

Коромыслов, В. В. (2006) Всеобщее как категориальный каркас сущности человека // Новые идеи в философии: актуальные проблемы научной философии : межвуз. сб. науч. трудов (по мат. Общероссийской науч. конф., Пермь, 13-15 апреля 2006 г.) : в 2 т. / гл. ред. В. В. Орлов. Пермь : Изд-во Пермского ун-та. Вып. 15. Т. 1. 365 с. С. 195-205.

Коромыслов, В. В. (2008) О подлинно-всеобщем // Инновационный потенциал аграрной науки - основа развития АПК : сб. по мат. Всероссийской науч.-практ. конф., посвященной 90-летию сельскохозяйственного образования на Урале (Пермь, 21 ноября 2008 г.). Пермь : Прокрост. Ч. 2. 302 с. C. $183-186$.

Любутин, К. Н., Кондрашев, П. Н. (2007) Диалектика повседневности. Методологический подход. Екатеринбург : УрГУ ; ИФиП УрО РАН ; РФО. 295 c.

Маркс, К. (1955) Тезисы о Фейербахе // Маркс К., Энгельс Ф. Соч. : в 50 т. 2-е изд. М. : Политиздат. Т. 3. XII, 629 с. С. 1-4.

Маркс, К. (1974) Экономическо-философские рукописи 1844 года // Маркс К., Энгельс Ф. Соч. : в 50 т. 2-е изд. М. : Политиздат. Т. 42. XXIV, 535 c. C. 41-174.

Мисабишвили, Ш. В. (1971) Диалектика общего и особенного в социальном развитии. Сухуми : Алашара. 247 с.

Мусаелян, Л. А. (2006) Концепция исторического процесса К. Маркса: человеческий контекст // Новые идеи в философии: актуальные проблемы научной философии : межвузовский сб. научных трудов (по материалам Общероссийской научной конференции, Пермь, 13-15 апреля 2006 г.) : в 2 т. / гл. ред. В. В. Орлов. Пермь : Изд-во Пермского ун-та. Вып. 15. Т. 1. 365 с. С. 44-59.

Новые идеи в философии (1992-2015) : межвуз. сб. науч. трудов по мат. Общероссийской науч. конф., проходившей в Перми в 1992-2015 гг. / гл. ред. В. В. Орлов. Пермь : Изд-во Пермского ун-та. Вып. 1-23. 
Орлов, В. В. (1999) История человеческого интеллекта: современный интеллект. Пермь : Изд-во Пермского ун-та. Ч. 3. 183 с.

Орлов, В. В. (2000) Научная философия в начале XXI века // Новые идеи в философии : межвуз. сб. науч. трудов по мат. Общероссийской науч. конф., проходившей в Перми 11-13 апреля 2000 г. / гл. ред. В. В. Орлов. Пермь : Изд-во Пермского ун-та. Вып. 9. 261 с. С. 3-12.

Философия пограничных проблем науки (1967-1975) : межвуз. сб. науч. ст. / гл. ред. В. В. Орлов. Пермь : Изд-во Пермского ун-та. Вып. 1-8.

Шимина, А. Н. (1982) О социальной форме всеобщего // Проблемы всеобщего в марксистской философии : сб. по мат. Общесоюзной конф., проходившей в Челябинске в марте 1982 г. Челябинск : Изд-во Челяб. гос. пед. унта. 166 с. С. $71-74$.

Дата поступления: 1.11.2018 г.

\section{REFERENCES}

Barg, O. A. (1997) Chelovek i mir: Kak materiia zastavliaet cheloveka ee uslozhniat' [The human and the world: How the matter forces the man to complicate it]. In: Novye idei $v$ filosofii [New ideas in philosophy] : An interuniversity collection of papers presented at the All-Russian conference, April 13-15, 1997 / ed. by V. V. Orlov. Perm : The Publishing House of Perm University. Issue 6. 164 p. Pp. 55-59. (In Russ.).

Vasilieva, T. S. (1999) Vseobshchii istoricheskii zakon [Universal law of history]. In: Novye idei $v$ filosofii [New ideas in philosophy] : An interuniversity collection of papers presented at the All-Russian conference, April 13-15, 1999 / ed. by V. V. Orlov. Perm : The Publishing House of Perm University. Issue 8. 316 p. Pp. 23-27. (In Russ.).

Ilienkov, E. V. (1984) Dialekticheskaia logika: ocherki istorii i teorii [Dialectical logic: Essays on the history and theory]. 2nd edn. Moscow : Politizdat Publ. 320 p. (In Russ.).

Kozin, N. G. (1994) Neobkhodimost' cheloveka [Necessity of the human]. In: Novye idei $v$ filosofii [New ideas in philosophy] : An interuniversity collection of papers presented at the All-Russian conference, April 10-12, 1994 / ed. by V. V. Orlov. Perm : The Publishing House of Perm University. Issue 2. 227 p. Pp. 100-109. (In Russ.).

Kontseptsiia edinogo, zakonomernogo mirovogo protsessa i sovremennost' [The concept of a single, global law-governed process and modernity] (1987) : Proceedings of the All-Union conference, March 24-28, 1987 / ed. by V. V. Orlov. Perm : Publishing House of Perm University. 327 p. (In Russ.).

Koromyslov, V. V. (2004) Sushchnost' cheloveka i problema vseobshchego [The essence of the man and the problem of universal]. In: Novye idei $v$ filosofii: Filosofiia $v$ sovremennoi Rossii [New ideas in philosophy: Philosophy in contemporary Russia] : An interuniversity collection of papers presented at the AllRussian conference, April 14-16, 2004 : in 2 vols. / ed. by V. V. Orlov. Perm : The 
Publishing House of Perm University. Issue 13. Vol. 1. 292 p. Pp. 214-218. (In Russ.).

Koromyslov, V. V. (2006) Vseobshchee kak kategorial'nyi karkas sushchnosti cheloveka [The universal as the categorical frame of the essence of the man]. In: Novye idei v filosofii: Aktual'nye problemy nauchnoi filosofii [New ideas in philosophy: Actual problems of scientific philosophy] : An interuniversity collection of papers presented at the All-Russian conference, April 13-15, 2006 : in 2 vols. / ed. by V. V. Orlov. Perm : The Publishing House of Perm University. Issue 15. Vol. 1. 365 p. Pp. 195-205. (In Russ.).

Koromyslov, V. V. (2008) O podlinno-vseobshchem [On the genuinely universal]. In: Innovatsionnyi potentsial agrarnoi nauki - osnova razvitiia APK [Innovation potential of agricultural science - the foundation for the development of the AIC] : Proceedings of the All-Russian conference, dedicated to the 90th anniversary of agricultural education in the Urals, November 21, 2008. Perm : Prokrost Publ. Pt. 2. 302 p. Pp. 183-186. (In Russ.).

Liubutin, K. N. and Kondrashev, P. N. (2007) Dialektika povsednevnosti. Metodologicheskii podkhod [The dialectics of everyday life. The methodological approach]. Yekaterinburg : The Publishing House of the Ural State University ; Institute of Philosophy and Law, Ural Branch, RAS ; Russian Philosophical Society. 295 p. (In Russ.).

Marx, K. (1955) Tezisy o Feierbakhe [Theses on Feuerbach]. In: Marx, K. and Engels, F. Sochineniia [Works] : in 50 vols. 2nd edn. Moscow : Politizdat Publ. Vol. 3. XII, 629 p. Pp. 1-4. (In Russ.).

Marx, K. (1974) Ekonomichesko-filosofskie rukopisi 1844 goda [Economic and philosophic manuscripts of 1844]. In: Marx, K. and Engels, F. Sochineniia [Works] : in 50 vols. 2nd edn. Moscow : Politizdat Publ. Vol. 42. 512 p. Pp. 43174. (In Russ.).

Misabishvili, Sh. V. (1971) Dialektika obshchego i osobennogo v sotsial'nom razvitii [The dialectics of the general and particular in social development]. Sukhumi, Alashara Publ. 247 p. (In Russ.).

Musaelian, L. A. (2006) Kontseptsiia istoricheskogo protsessa K. Marksa: chelovecheskii kontekst [K. Marx’s conception of the historical process: The human context]. In: Novye idei v filosofii: Aktual'nye problemy nauchnoi filosofii [New ideas in philosophy: Actual problems of scientific philosophy] : An interuniversity collection of papers presented at the All-Russian conference, April 13-15, 2006 : in 2 vols. / ed. by V. V. Orlov. Perm : The Publishing House of Perm University. Issue 15. Vol. 1. 365 p. Pp. 44-59. (In Russ.).

Novye idei $v$ filosofii [New ideas in philosophy] (1992-2015) : An interuniversity collection of papers presented the All-Russian conference, April, 19922015 / ed. by V. V. Orlov. Perm : The Publishing House of Perm University. Issues 1-23. (In Russ.).

Orlov, V. V. (1999) Istoriia chelovecheskogo intellekta: Sovremennyi intellekt [The history of the human intellect: Modern intelligence]. Perm : The Publishing House of Perm University. Pt. 3. 183 p. (In Russ.). 
Orlov, V. V. (2000) Nauchnaia filosofiia v nachale XXI veka [Scientific philosophy at the beginning of the 21st century]. In: Novye idei $v$ filosofii [New ideas in philosophy] : An interuniversity collection of papers presented at the AllRussian conference, April 11-13, 2000 / ed. by V. V. Orlov. Perm : The Publishing House of Perm University. Issue 9. 261 p. Pp. 3-12. (In Russ.).

Filosofiia pogranichnykh problem nauki [Philosophy of the border problems of science] (1967-1975) : An interuniversity collection of papers / ed. by V. V. Orlov. Perm : The Publishing House of Perm University. Issues 1-8. (In Russ.).

Shimina, A. N. (1982) O sotsial'noi forme vseobshchego [On the social form of the universal]. In: Problemy vseobshchego v marksistskoi filosofii [Problems of the universal in Marxist philosophy] : Proceedings of the All-Union conference, March, 1982. Chelyabinsk, The Publishing House of Chelyabinsk State Pedagogical University. 166 p. Pp. 71-74. (In Russ.).

Submission date: 1.11.2018.

Коромыслов Виталий Валерьевич - кандидат философских наук, доцент кафедры философии Пермского государственного аграрнотехнологического университета имени Д. Н. Прянишникова. Адрес: 614990, г. Пермь, ул. Петропавловская, 23. Тел.: +7 (342) 240-56-57. Эл. адрес: vvk79@mail.ru

Koromyslov Vitaly Valerievich, Candidate of Philosophy, Associate Professor, Department of Philosophy, D. N. Pryanishnikov Perm State Agrarian and Technological University. Postal address: 23 Petropavlovskaya St., 614990 Perm, Russian Federation. Tel.: +7 (342) 240-56-57. E-mail: vvk79@mail.ru

SPIN-код РИНЦ: 1558-9950

ORCID: 0000-0001-6115-3631

\section{Для ичитирования:}

Коромыслов В. В. Проблема социально-всеобщего в контексте конкретно-всеобщей теории развития [Электронный ресурс] // Горизонты гуманитарного знания. 2019. № 1. C. 108-119. URL: http://journals.mosgu.ru/ ggz/article/view/954 (дата обращения: дд.мм.гггг). DOI: 10.17805/ggz.2019.1.6 